\title{
Tracking Utilizing Accelerometer and Piezoelectric Sensor
}

\author{
Joshua So Gulmatico ${ }^{1}$, Alvin Sarraga Alon ${ }^{2}$, Mon Arjay Fernandez Malbog ${ }^{3}$, Rufo I. Marasigan Jr. \\ ${ }^{1}$ Technological Institute of the Philippines, Philippines, jgulmatico.cs@ @ip.edu.ph \\ ${ }^{2}$ Technological Institute of the Philippines, Philippines, aalon.cpe@ tip.edu.ph \\ ${ }^{3}$ Technological Institute of the Philippines, Philippines, malbog.monarjay@ gmail.com \\ ${ }^{4}$ Technological Institute of the Philippines, Philippines, rufo.marasigan.jr@tip.edu.ph
}

\begin{abstract}
Car Accident is one of the causes of death in every country. The problem is that the way of assistance for the victim is un-established in the Philippines. This paper develops an embedded system that will help detect a car accident and afterward send a notification to the nearest Police Station and Emergency Response Team for immediate assistance. This system will also send an SMS to the Family of the victim. It was utilizing the Accelerometer, Piezoelectric Sensor, and GPS module to track the location of a car that encounters an accident. Also, with the use of the Google Map API, a notification message will be sent automatically to the nearest Police Station and Emergency Response Team web server so they can take action immediately. Other works that are somewhat similar to this paper prove the effectivity and good outcome it can give to society. Therefore, this system contributes to saving lives through immediate action from the nearest Police Station and Emergency Response Team that this study aims to do.
\end{abstract}

Key words: Accelerometer, car accident detection, google map API, piezoelectric sensor, web server

\section{INTRODUCTION}

[1] A car accident commonly results in injury, damage to property, and worst case, death. [2] Based on the study of WHO (World Health Organization) last 2015, almost 1.25 million people died because of a road accident, and half a million of that is from the Philippines. This study aims to create an embedded system that will help lessen the injury and the continuous loss of lives of the victim. The lack of advanced technology is one of the reasons that hinder the Philippines to give immediate action to those kinds of accidents. Through using different sensors, such as Accelerometer, Piezoelectric Sensor, and GPS module, this study will track the location of the car involved in an accident. After that, it will send a notification to the nearest Police Station and Emergency Response Team to asks for immediate assistance. It will also send an SMS message to the Family of the victim to inform them about the accident that their loved one encounters. In that case, we can prevent more damage and help the victim to get at least first aid to lessen the injury.

\section{RELATED WORKS}

\subsection{Local and Global Road Accidents situation}

[3] Murray and Lopez stated in the study that road accident is the tenth cause of death globally. Road accidents victimize almost 1.2 million. Most of the victims admitted to different orthopedic centers because of the injury. It stated that the victim is mostly male aged 15 to 44 years old. It is a burden to the economy because they lost many workers for the Family. If this issue continues to grow, considering that road accident as the third leading cause of injury by 2020 .

[4] The rate of road accidents from the developed countries since 1960 seems to decrease because of the law implementation of the law. Such law is driving safely with the seat belt, cannot drive if you are under the influence of alcohol, and much more. It is said effective because in the United States, which is considered a developed country, have a low rate in terms of road accidents and some country such as Malaysia that is just growing high.

[5] The most victim in the road accident is aged 15 - 44 years old, which is assuming that the one who provides for their Family. The cost of this loss is very high because of this. It reported that those Family that lost their loved one decrease their standard of living following to their loss.

[6] The leading cause of road accidents is driving at maximum speed, driving without proper gear or a seat belt, sleepy while driving, and the most common cause, driving under the influence of drugs or alcohol.

[7] Some developed countries also increased in rate of road accidents. It is because the number of the car in their country also increase and because of that, they are more prone to road accidents. Lack of police enforcement on the road and weak road signs are two of the reason why even if they are considered a developed country, they are also not exempted in terms of road accidents.

[8] Not all the victims of road accidents are the one who owns a car. Some of the victims are pedestrians who prefer to cross the dangerous road instead of using pedestrian bridges. One of the solutions they think to reduce the exposure of pedestrian to road accidents is by promoting efficient patterns and land use. [9] Another solution to lessen road accidents is to separate the bicycle lane from private cars and public transportation. Just like in Denmark, this solution reduced the death of the cyclist by 35 percent. This country is the one we should take as an example to have a well built and compelling road safety law. 
[10] Road accidents tend to occur mostly during the day. It is because traffic during the day is higher than at dawn and night.

[11] Accidents mainly occur on curved and inclined roads. The type of way affects the occurrence of an accident. The crashes from vertical and horizontal curves likely to contribute to the capacitating injury.

\subsection{Car Accident Detection using Accelerometer, GPS and GSM module}

[12] Technology gives comfort in our lives and makes our work easier. However, advantages always come with disadvantages. One of the disadvantages of it is, it increased traffic hazards and road accidents. The results of it are injury, damage to property, and worst, death. Thus, this system provides an optimum solution to the problem. With the use of Accelerometer and GPS module, the embedded system will try to locate the location of the car once it encounters accidents. Afterward, it will send an SMS message to the Hospital and Authority to ask for immediate medical and security assistance through the use GSM module. This study aims to lessen injury and loss of lives because of an accident by taking immediate action. [13] The study bears a similarity to the previous study. Nowadays, the modern world, one's safety is very important because anything can happen within a period. Road accident is not predictable, and so we need to be very extra careful while on the road. With the use of Accelerometer can detect if one's car is in the accident once the $\mathrm{x}, \mathrm{y}$, and $\mathrm{z}$ axial formation change. GPS module can locate the location, and with the use of a GSM module, it can also send SMS messages to the hospital. This study aims to save the lives of people and avoid the huge loss of it.

\subsection{Synthesis of the Study}

The Literature and Studies we gather will serve as the basis for our study. Related Literature consists of many studies that will prove that the study we are proposing can be a great contribution to society. The statistics that we gather show the number of people dying because of car accidents. It also shows the age bracket that is mostly involved in car accidents. Since our study composed of sensors that can use for car accident detection, it will automatically sense when a car encountered an accident. There will be no reason for the drivers to use their phones while driving or during the accident. [14] With the technology that the drivers are adopting, things transform into digital to make things easier and reachable without effort.

\section{METHODOLOGY}

3.1 System Architecture

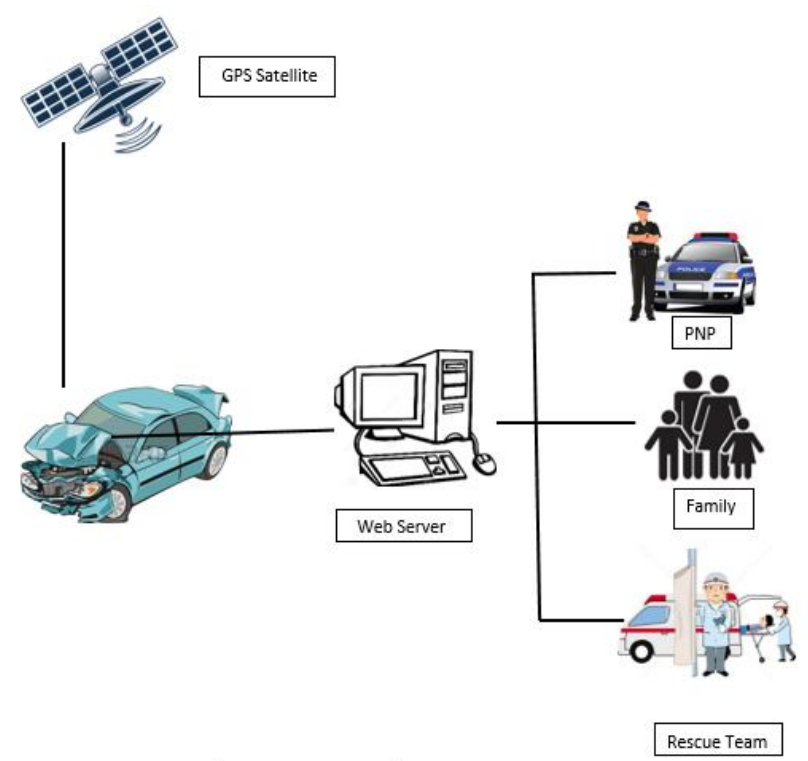

Figure 1: System Architecture

This embedded system will connect to the GPS satellite with the use of GPS module and once the sensors are triggered, which is: Piezoelectric Sensor for Pressure and Accelerometer to get the $\mathrm{x}, \mathrm{y}$, and $\mathrm{z}$ axial formation of a car. Once the sensor is triggered, the embedded system will assume that there is an accident, and so it will show the nearest Police Station and Emergency Response Team with the help of Google Map API. The nearest Police Station and Emergency Response Team will receive notification of the location and the information about the accident through their web server. On the other hand, a message to the Family of the victim through an SMS message.

\subsection{Hardware Design}

3.2.1 Arduino Uno - The Arduino Uno is a microcontroller board based on the ATmega328 (datasheet). It has 14 digital input/output pins (of which six can function as PWM outputs), six analog inputs, a $16 \mathrm{MHz}$ crystal oscillator, a USB connection, a power jack, an ICSP header, and a reset button. Uno board is enough because it is already pre-built with every microcontroller support and plug in the USB cable.

3.2.2 GPS Shield - Used to sends alert SMS with the coordinates and link to Google Maps with the help of GPS technology for satellite navigation to the family, PNP and rescue team.

3.2.3 Accelerometer - Used to detect accidents or sudden changes in its $\mathrm{x}, \mathrm{y}$, and $\mathrm{z}$-axis. It measures the static acceleration of gravity when the Accelerometer is tilted and measures the dynamic acceleration, which will help to detect the change of vibration that may occur.

3.2.4 Piezoelectric Sensor - is an electric component that measures or detects changes in pressure, acceleration, strain, or force by converting them to an electrical charge. The study 
will use this as a combination of the Accelerometer for an accurate result.

3.2.5 Wi-Fi Module - a self-contained SOC with integrated TCP/IP protocol stack that can give any microcontroller access to your Wi-Fi network. The web server needs this to get information from the hardware.

3.2.6 LCD Display - Used to display the results of the accidents captured by the sensors and GPS location.

3.2.7 Buzzer and 9V Battery - The buzzer produces sound if sensors are triggered so it can alert the people around the vicinity of the accident and $9 \mathrm{v}$ battery for power supply.

\subsection{Participant and Evaluation}

The participants of this study are only College Students to have different views and opinions other than those who own a car. For the evaluation criteria, we will be using the ISO 9126's software quality criteria to evaluate the embedded system.

Table 1: Ratings and Interpretation

\begin{tabular}{|c|c|}
\hline Ratings & Interpretation \\
\hline 5 & Highly Acceptable \\
\hline 4 & Acceptable \\
\hline 3 & Moderately Acceptable \\
\hline 2 & Slightly Acceptable \\
\hline 1 & Need for Improvement \\
\hline
\end{tabular}

Table 1 represents the legend used for the research evaluation. The proponents used this scale as a guide to interpreting the assessment of the research.

\section{RESULTS}

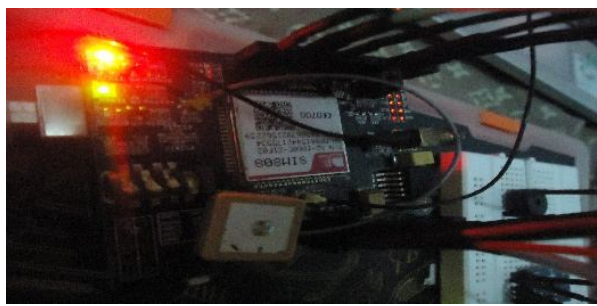

Figure 2: GPS module connected on Breadboard

GPS module will contribute to the study by tracking the location of one's car that has the system and encounters an accident.

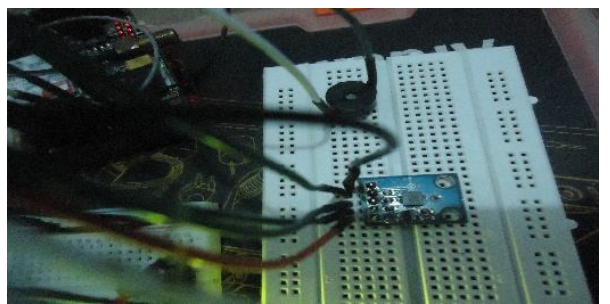

Figure 3: Accelerometer connected to Breadboard

Accelerometer helps detect the $\mathrm{x}, \mathrm{y}$, and $\mathrm{z}$ axial formation of a thing related to it when it is triggered. This system helps the researcher to know the changes occurring on a car depends on the changes of value in an Accelerometer. The cost of it will be measured based on the threshold that inputted in it.

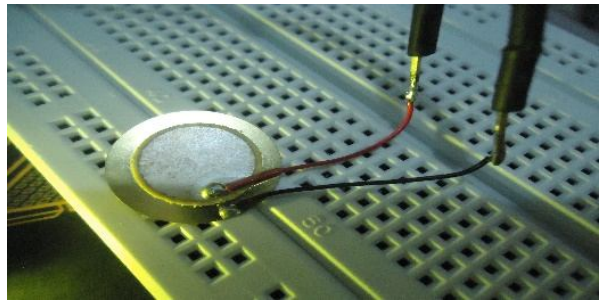

Figure 4: Piezoelectric Sensor connected to Breadboard

Piezoelectric Sensor will detect the pressure of a car once it crashes and bumps with a strong force. It is essential to the study because it will help the researcher know if there is an accident or none. The pressure will be measured based on the threshold that inputted in it.

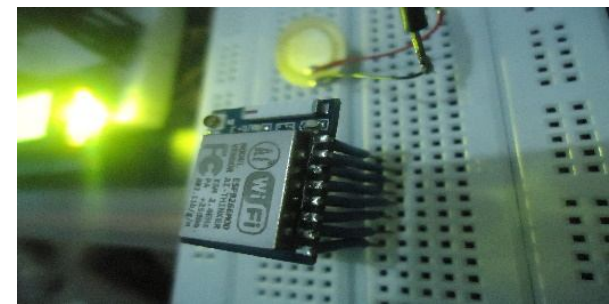

Figure 5: Wi-Fi module connected to Breadboard

Used to send data, such as the axial formation of a car and the pressure, will be sent to the webserver.

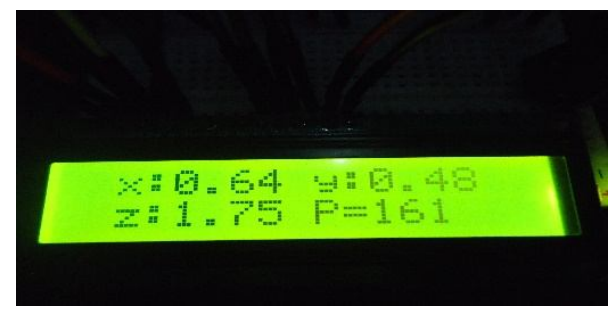

Figure 6: LCD Display

It displays the $\mathrm{x}, \mathrm{y}$, and $\mathrm{z}$ axial formation as well as the pressure through Accelerometer and Piezoelectric Sensor. The importance of this one is for the user to know personally the changes happening in their car.

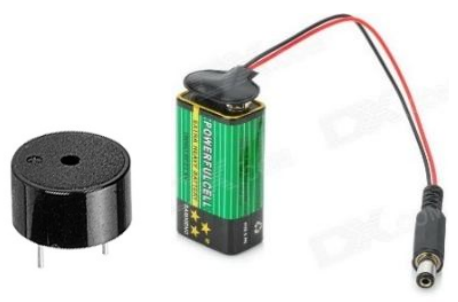

Figure 7: Buzzer and 9V Battery

The buzzer produces sound when sensors are triggered to send alert the people around the vicinity of the accident and $9 \mathrm{v}$ battery for power supply. 


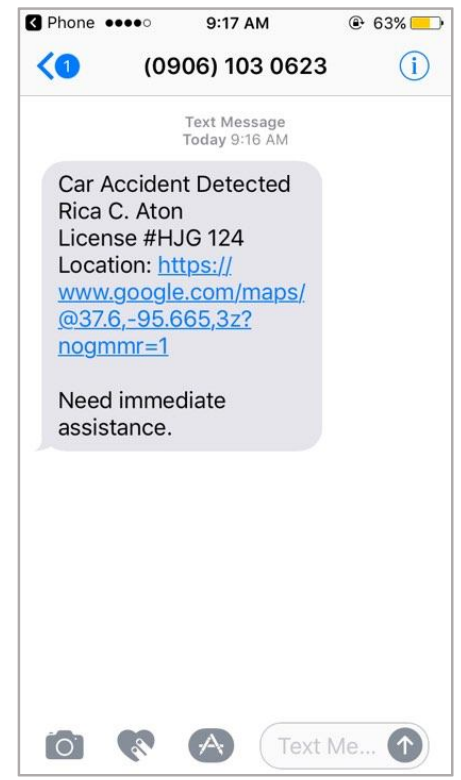

Figure 8: Example of text message to Family

This example message shows the interface of a message that the Family will receive from the webserver.

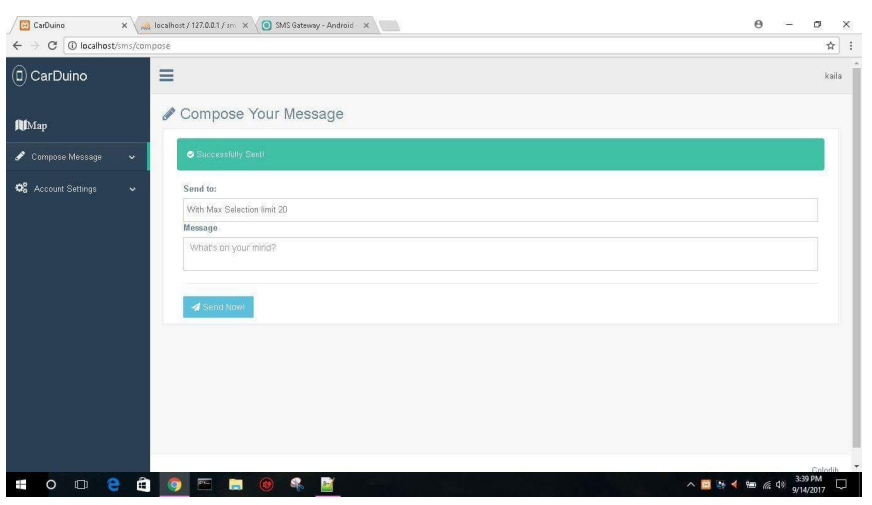

Figure 9: Compose Message in webserver

The compose message sample in the webserver is sent to the representative receiver.

\section{SUMMARY}

The main goal of this study is to develop an embedded system that will help to detect car accidents using Accelerometer, Piezoelectric Sensor, GPS module, and Google Map API and send SMS messages to Family. Notification message automatically sent to the nearest Police Station and Emergency Response Team. The researchers came up with the specific objectives: to create an embedded system to detect accidents using Accelerometer and Piezoelectric Sensor. A displayed message shows the pressure takes place on the car, and to give information about the vehicle position regarding the $\mathrm{X}, \mathrm{Y}$ and $\mathrm{Z}$ axis, to be able to track the location of the accident in the form of latitude and longitude, GPS sent the coordinates to the respective receiver. Notification through SMS to the family member and to be able to notify the nearest Police Station and Emergency Response Team to asks for immediate security and medical assistance.

This research and development of the study were built on time and in almost five months starting from Capstone 1 in summer through Capstone 2 for the first half of the semester. This study used different methods and tools such as Arduino IDE, Notepad, XAMPP, Arduino Uno, GPS Shield, Accelerometer, Piezoelectric Sensor, Wi-Fi Module, LCD Display, Buzzer. And $9 \mathrm{~V}$ battery to develop the study and make it possible. The objectives were met based on the result of the evaluation assessed by the group of the respondents.

\section{CONCLUSION}

With the comprehensive study and the conducted software evaluation from students and professionals, this study performs the following:

1. The research concludes that the developers can produce an embedded system that will detect car accidents and notify the nearest Police Station and Emergency Response Team with the use of a web server to asks for security and medical assistance.

2. The research concludes that the developers can produce hardware that can send an SMS message to the Family using the webserver.

\section{REFERENCES}

1. Tamayo, A. Occurrence of Traffic Accidents in the Philippines: An Application of Poisson Regression Analysis. Based on the study of the World Health Organization. 2009. https://doi.org/10.2139/ssrn.1438478

2. J. Clerk Maxwell. A Treatise on Electricity and Magnetism. Oxford: Clarendon. 3rd ed., vol. 2. pp.68-73. 1892.

3. Murray, C.J., and Lopez, A.D. eds. The Global Burden of Disease: A Comprehensive Assessment of Mortality and Disability from Diseases, Injuries, and Risk Factors in 1990 and Projected in 2020. Harvard School of Public Health, Boston. 1996.

4. Kopits, E. and Cropper, M. Traffic Fatalities and Economic Growth, The World Bank. World Bank, Washington, DC. Policy Research Working Paper No. 3035. 2003.

5. Peden, M. and Hyder, A.A. Road Traffic Injuries are a Global Public Health Problem. British Medical Journal. 324, no. 7346, 1153. 2002.

6. Nantulya, V.M. et al. Introduction: The Global Challenge of Road Traffic Injuries: Can We Achieve Equity in Safety? Injury Control and Safety Promotion 10, no. 1-2: 3-7. 2003. https://doi.org/10.1076/icsp.10.1.3.14109

7. WHO. Report of the Regional Director to the Regional Committee for the Western Pacific. Manila: WHO: 96-99. 2003.

8. Hijar, M. et al. Pedestrian Traffic Injuries in Mexico: A Country Update,\&quot; Injury Control and Safety Promotion 10, no. 1-2 (2003): 37-43; S.N. Forjuoh, \&quot. Traffic-Related Injury Prevention Interventions for Low-Income Countries,\&quot; Injury Control and Safety Promotion. 10, no. 1-2. 2003. 109-18; and M. Mutto et al., \&quot. The Effect of an Overpass on Pedestrian 
Injuries on a Major Highway in Kampala. Uganda, African Health Science 2, no. 3. 89-93. 2002.

9. Herrstedt, L. Planning and Safety of Bicycles in Urban Areas,\&quot; in Proceedings of the Traffic Safety on Two Continents Conference. Lisbon. Sept. 22-24, 1997. Linköping: Swedish National Road and Transport Research Institute. 43-58. 1997.

10. Williams, M. and Hoffmann, E. Motorcycle Conspicuity and Traffic Accidents Accident Analysis and Prevention. 11, 209-224. 1978.

11. Savolainen, P. and Mannering, F. Probabilistic models of motorcyclists' injury severities in single and multi-vehicle crashes Accident Analysis and Prevention. 39, 955-963. And Communication Engineering, 3 (4) 3506-3511. https://doi.org/10.1016/j.aap.2006.12.016

12. Shah, D., Nair, R., Parikh, Vaibhav., and Shah, Viraj. Accident Alarm System using GSM, GPS and Accelerometer, International Journal of Innovative Research in Computer

13. Sulochana, B. and Babu, S.M. Monitoring and Detecting Vehicle Based On Accelerometer and MEMS Using GSM and GPS Technologies. International Journal of Computer Science Trends and Technology (IJCST). 2 (4) 55-59

14. B. Malubaya, G. Wang. Real-time Parking Information System with Cloud Computing Open Architecture Approach. International Journal of Emerging Trends in Engineering Research (IJETER). Vol. 8, No. 1, Jan 2020

https://doi.org/10.30534/ijeter/2020/04812020. 